\title{
Minimizing the Negative Externality from Sachet Water Consumption in Nigeria
}

\author{
Urama Nathaniel E. ${ }^{{ }^{*}}$ \\ Department of Economics, \\ University of Nigeria Nsukka, Nigeria \\ unathaniel@ymail.com \\ Ukwueze Romanus E. \\ Department of Economics, \\ University of Nigeria Nsukka, Nigeria \\ Aneke Gladys C. \\ Department of Economics, \\ University of Nigeria Nsukka, Nigeria \\ *E-mail of the Corresponding author: unathaniel@ymail.com
}

\begin{abstract}
:
Over the years, there has been a consistent increase in the production and use of plastic and sachet packaged products in Nigeria which results in a proportional increase in plastic and Nylon waste pollution in the environment. An earlier survey show that the introduction of sachet water in the country some years ago worsened the situation as it contributes to more than $60 \%$ of the sachet pollution. This study therefore tried to find out an efficient and sustainable means of collecting the used sachet water bags to minimize its negative external impact on the environment. It was carried out using primary data collected through direct interview from a sample of 1500 individual in some selected states in the Country. The data was analysed using descriptive statistics and Log-log regression model. The results of the analysis show that PPP method can be effective in managing the menace. Majority of the sampled individuals are of the opinion that a $100 \%$ PPP levy will be a sufficient motivation for sachet water users to return their used sachet water bags to the appropriate collection sites in return for their levy or for the trash pickers to collect them for an equivalent payment.
\end{abstract}

Keywords: Sachet water, biodegradable, Pollution, Externality, Plastic Polluter Pay (PPP)

\subsection{Introduction}

About three billion people as at 2010 lacks save sanitation. Within 20 years' time, it is expected that an additional two billion will live in towns and cities, mainly in developing countries, demanding sanitation. Target 10 of the millennium development goals is to half by 2015 , the proportion of people without suitable access to save drinking water and basic sanitation (WHO, 2010). The 2010 United Nations summit highlights that at the current rate of progress, the world will miss the target. The world health organization (WHO) also warns that the target will be missed by half a billion people, most of them in rural Africa and Asia. In their March 2012 joint news report, WHO/ UNICEF, provides the latest update on rural areas across the globe, highlighting the need for greater attention both to water and sanitation. The report highlights, that the world is still far from meeting the MDG target for sanitation, and is unlikely to do so by 2015 . It has it that only $63 \%$ of the world now have improved sanitation access, a figure projected to increase only to $67 \%$ by 2015 , well below the $75 \%$ aim in the MDGs. Currently 2.5 billion people still lack improved sanitation (WHO/ UNICEF, 2012). In Africa, this is attributed largely to massive generation and poor management of non-biodegradable wastes.

During the pre-oil boom era, for example, food and paper material constituted more than $55 \%$ of the municipal solid wastes (MSW) in Nigeria with plastic material constituting only about $1 \%$. However, this has changed significantly in the past decade due to increased incomes and changes in lifestyles associated with the oil boom. Currently, plastic wastes contribute to more than $65 \%$ of the municipal solid waste in Nigeria, with food and paper waste making up the rest (Globe Net Market Report, 2005). A research carries out by Okeniyi and Anwam in 2012 found out that plastic related materials constitute sizeable portion of the solid wastes generated in Covenant University (Okeniyi and Anwam, (2012).

These plastic and Nylon waste materials are often randomly discarded, creating waste-disposal problems in many Nigerian cities. The economic and environmental impacts of this plastic waste is increasing significantly as they clog domestic sewages systems, choking water drains, threatening aquatic life in receiving water systems, often causing soil degradation, reducing biodiversity and the aesthetic quality of city parks and beaches (Adewimi, 2006). This makes a mockery of our quest to make tourism our second foreign exchange earner, to relieve the hard pressed oil sector. For the fishing industry, it spells doom to an already wrecked industry. Taking a walk around the foodstuffs markets in Nigeria, reveals that medium and normal sized fish have gone almost extinct in our waters. Usman et al, (2012) links the recent unprecedented flood witnessed in some cities of Nigeria to the clogging of drainages by water sachet waste. They said that 
the challenge posed by water sachet waste and other polymer or plastic waste in the country is particularly daunting due to their non-biodegradable nature

\subsection{Problem statement}

The problem of solid waste management in general and plastic in particular is a growing source of concern in Africa.It is identified as one of the major challenges in the promotion of sustainable production and consumption in the region (Adewumi, 2006). In Nigeria, this has posed a serious threat to urban development for it undermines and destroys the aesthetics of the country's cities, and is a health hazard to the citizens. Offion in Jan, 2012 Nigerian Observer for instance reports that Waste management has been a daunting challenge to the Lagos State Government, as the huge population of more than seven million generate 9,000 metric tons of waste daily.

The generation of solid wastes has been increasing steadily over the years in Nigeria, due to rising population, urbanization and industrialization with increasing plastic and sachet packaging approach (Nkwoh, 2006: 2).

Despite being the most recent among the plastic and nylon waste generating industries, the sachet water industries currently generate more than half of the municipal solid waste in Nigeria and other African Countries. Edoga et al. (2008) noted that more than $70 \%$ of Nigerian adults drink at least one sachet of water daily resulting to about 50 to 60 million used water-sachets disposed daily across the country. A reconnaissance survey carried out in 2005 found that nylon waste from sachet water supply and demand chains constitute about $80 \%$ of the plastic and nylon waste material in Nigerian (Adekunle et al, 2005).

Some countries like Uganda adopted the policy of outright ban of the production and use of these materials. This however, is not an economic solution to the problem since it will lead to the closure of the industry, displacing many workers and worsening the problem of unemployment already at its peak in Nigeria. More so, the average Nigerians are in dire need of the product and any action that will close the company will reducing the welfare of the people as the government is not ready for the alternative.

An alternative approach of reducing the pollution effect to a bearable level was initially used by the Indo-Mie industry in Nigeria: paying the children to collect these wastes for recycling and proper management. This can be adopted by taxing these industries so as to get the revenue that will be used to pay the children. This approach called Plastic Polluter Pay (PPP) was inherent in the Pigovan tax introduced by Arthur Pigou to internalize externalities. This is also in accordance with the findings of Babatunji and Biala, (2010) which they called Deposit Refund System. The effectiveness of this however as acknowledged by even the developers depends on being able to fix the taxes that will be equal to the marginal social cost of the goods and services. This also requires the knowledge of the price elasticity of the product.

It is therefore, the question of what should be the appropriate amount of per unit tax on these products that will solve the dual purpose of being enough to pay for their refuse collection without significantly affecting the working of the industry that this work seeks to address.

The broad objective of the research is therefore, to develop an effective means of collecting the used water sachets for recycling or proper management.

The specific objectives are to:

* determine the minimum amount of money that is needed to fund the collection of the used water sachets

* determine how price elastic the demand and supply of sachet water is

\subsection{Scope of the study}

This research work was limited to the sachet water industries as it contributes to more than half of the pollution. The survey work will be carried out in Lagos, Anambra and Enugu states only.

\subsection{The origin and state of sachet packaging in sub-Saharan Africa}

Packaging process dates back to medieval times when in those days packaging was perceived as a simple process of wrapping with leaves and tree barks. Historically, it has undergone considerable revolution over the centuries and transgressing from the simple process to more sophisticated industrial packaging technology today (Fobil and Hogarh, 2003). In those olden days, food products were carried in leaves from markets and from commercial centres, in palm fronts and in banana leaves from farms in the rural areas. Until as late as in the 70s, leaves were still used as packaging materials in the sale of food by way side food vendors in the major cities across the sub-region (KMA, 1995; Scheizer and Annoh, 1996; Archer et al., 1997).

Over time, however, pressurised to lift food and water packaging standards by public health authorities, the business community switched to the use of paper as conventional packaging materials. Later in the late 1980s and early 1990 s the use of paper in conventional packaging gave way for nylon bags and other plastics as stringent quality standards were required in food and water packaging industries so as to minimize the incidence of food and water related epidemics.

Several properties of polyethylene films make them unique and give them comparative advantage over the other packaging materials such as leaves and paper that were previously in use. They are lightweight, tough, inert and relatively 
un-reactive. These properties make them more convenient as carrier and hygienic packaging materials as compared to paper and leaves (Fobil and Hogarh, 2003) This has made the volume of plastic fractions in municipal solid wastes (MSW) in the region to increase progressively within the last two decades. In Nigeria, the addition increase may also be traced to the continued water shortage and the approval of more sachet water industry by the National Agency for Foods and Drugs Administration and Control (NAFDAC)(Adewumi, 2006).

\subsection{Waste Disposal Practice in Nigeria}

Currently, Nigeria has no effective anti-littering law or any specific policy on plastic waste management. The few municipality by-laws prohibiting littering are not enforced and even where they are, appropriate disposing infrastructures are deficient. Waste management in Nigeria where available are scattered, scanty, obsolete and non-enforceable. Hence, it does not serve as a deterrent to indiscriminate dumping of refuse. This absence of a coherent waste disposing policy has caused accumulation of waste and adversely affected economic development in Nigeria (Globe net market report, 2007).

\subsection{Theoretical Framework}

Since the key issue here is pollution from sachet water consumption which affects both those involved and those that are not (externality), the framework for the model is based on the well-known externality and Pigovian tax. An externality is cost or benefit that is not transmitted through prices and is incurred by a party who was not involved in the transaction causing the cost or benefit. Arthur Pigou who developed the concept of externality argues that the value of any commodity or transaction should be made up of the economic cost and the social cost but most at times the market price of these goods and services are computed using only the economic cost. This he said was because, the producers and consumers seek their own marginal private interest. When the marginal social interest diverges from the marginal private interest, they have no incentive to internalize the cost of the marginal social cost. A Pigovian tax is a tax applied to a market activity that generates negative externalities. The tax should be equal to the social cost and is intended to correct the market outcome. In the presence of negative externalities, the social cost of a market activity is not covered by the private cost of the activity. In such a case, the market outcome is not efficient and may lead to over-consumption of the product. A Pigovian tax equal to the negative externality is thought to correct the market outcome back to efficiency.

Though we are aware of the criticisms of the Pigovian tax system as a means of correcting for externality like that of difficulty in measuring social cost from Pigou (1920) himself and Baumol (1972), the reciprocal cost problem from Coase (1960), the political problem from Thompson and Batchelder (1974) we still believe that the little departure of the model from the Pigovian tax in the sense that it involves cash refund corrects for majority of these shortfalls.

\subsection{Methodology}

In PPP levy system, weighted proportion of the levy should be borne by producers of the sachet water and a corresponding weighted proportion also borne by the consumers who patronise the sachet water producers. This production pollution levy will be a fraction of the quantity of sachet water bags produced by the producer, which then can return into the environment as pollution, if not well disposed. Now, consumers of sachet water incur consumption pollution charges as part of the market price of sachet water. This will be a certain percentage of the production pollution charges (social cost) calculated based on the rate of consumption. The consumer PPP levy is meant to instil discipline in consumers regarding the way they dispose sachet water bags and this levy is retrievable by the consumer based on a tax refund system (or cashback), which is part of the proposed levy system.

The administration of the PPP levy system would be such that several sachet water bag collection points should be set up at strategic points in towns and cities across the country. This should give sachet water consumers or thrash pickers an opportunity to be given cash back when they return used sachet water bags to any of these points. In this case, when one drinks sachet water, there is financial motivation to return them in exchange for cash-back to the collection points (Fobill and Hogarh, 2003). This approach is very important for as revealed by Mojekeh, and Eze (2011), the empty sacs of sachet water waste is not really a problem; rather, it is the poor attitude of the consumer's and inhabitants of commercial cities and also lack of education on proper management, disposal and recycling technique.

The survey was conducted in three states in Nigeria; Lagos, Anambra and Enugu state in 2010. In each state, one city was selected and in each of the city, sample of 500 respondents were randomly selected. This gave a total of 1500 respondents. Both questionnaire and oral interviews were used to collect information from households and individual that falls within the sample. The sampling was done with the aid of national Bureau of Statistics (NBS) sampling frame. The data collected were analysed using deceptive statistics and regression analysis as detailed in section 3.2 below. The Log-Log model that was used to capture objective number two as shown in equation 1 section 3.2 is in accordance with econometrics approach. See Gujarati (2006, p175).

\subsection{The Model}

Different models were designed to capture different objectives of the study. 
I. Descriptive statistics were used to capture objective one; minimum amount of Naira that is needed for the collection of the used water sachets.

II. The second objective of the work; how price elastic is the demand and supply of sachet water will be captured using double log model as follows;

$$
\operatorname{In} Q_{X}^{d}=\operatorname{In} \alpha_{0}+\alpha_{1} \operatorname{In} P_{x}+\alpha_{2} \operatorname{In} P_{y}+\alpha_{3} \operatorname{In} P_{z}+\alpha_{4} \operatorname{In} Y+\mu
$$

Where In stands for natural logarithm

$Q_{X}^{d}=$ quantity demanded of sachet water at various prices per day.

$P_{x}=$ Price of sachet water/litre, $P_{y}=$ Price of bottled water/litre,

$P_{z}=$ Price of soft drinks/litre, and $\mathrm{Y}=$ income of the consumer.

Model (1) will capture both the price, cross and income elasticity of sachet water demand.

\subsection{Survey and Analytical Results}

The survey results show that more than $90 \%$ of the respondents believed that sachet water production and consumption poses a lot of danger to our environment. The remaining $10 \%$ are distributed among those who claim that sachet water production and consumption does not constitute any environmental nuisance, and those who said that it is not the production and consumption of sachet water that constitute the problem but the kind of people that produce and consume it and hence were indecisive. More than $60 \%$ of them would accept the opinion of PPP and less than $30 \%$ of the respondents were of the opinion that there should be an outright ban of sachet water production.

On the issue of the appriopriate ammount as a percentage of sachet water price that will be sufficient to fund the PPP programme with little or no effect on the rate of sachet water consumption, the results as shown in figure 3 was obtained. Majority of the respondent (53\%) are of the opinion that a PPP levy of $100 \%$ of sachet water price will be sufficient to fund the PPP programme. $25 \%$ of the respondent were supported a PPP levy of $80 \%, 13 \%$ suppoted a PPP levy of $70 \%, 7 \%$ supported $120 \%$ while as low as $2 \%$ were in support of $130 \%$.

Using the sample data collected with regards to the various quantities of sachet water that will be demanded given varioe prices of sachet water, botled water, soft drinks and the consumers income, the model of equation (1), gave the result contained in table 1 . The coefficient of $P_{x}$, the price of sachet water is -0.9321 . This shows that there is a negative relationship between the quantity of sachet water demanded and its price. There fore, increase in the price of sachet water will lead to a decrease in the quantity demanded of it. However, since the coefficient is less than one in absolute value, the demand for sachet water is price inelastic. An increase in the price brings about less than propotionate decrease in the quantity demanded. Specifically, 1 percent increase in the price of sachet water brings about $0.9 \%$ decrease in the qauntity demanded. The $\mathrm{t}$-value and the p-value of the coefficient of Px show that it is statistically significantly different from zero at $5 \%$ level of significance.

The coefficient of $\mathrm{P}_{\mathrm{y}}$, the price of botled water is 0.8743 . This shows that there is a positive relationship between the quantity of sachet water demanded and the price of botled water. There fore, increase in the price of botled water will lead to an increase in the quantity demanded of sachet water. However, since the coefficient is less than one in absolute value, the demand for sachet water is cross-price inelastic. An increase in the price of botled water brings about less than propotionate increase in the quantity demanded of sachet water. Specifically, 1 percent increase in the price of botled water brings about $0.87 \%$ decrease in the qauntity demanded of sachet water. The t-value and the p-value of the coefficient of $\mathrm{P}_{\mathrm{y}}$ show that it is statistically significantly different from zero at $5 \%$ level of significance.

The coefficient of $\mathrm{P}_{\mathrm{z}}$, the price of soft drinks is 0.2004 . This shows that there is a positive relationship between the quantity of sachet water demanded and the price of soft drinks. There fore, increase in the price of soft drinks will lead to an increase in the quantity demanded of sachet water. However, the $t$-value and the p-value of the coefficient of $P_{z}$ show that it is not statistically significantly different from zero at $5 \%$ level of significance. This means that there is statistically significant relationship between the price os soft drinks and the qauntity of sachet water demanded.

The coefficient of $Y$, the income of the consumer is -0.0035 . This shows that there is a negative relationship between the quantity of sachet water demanded and the income of the consumer. There fore, increase in income of the consumer will lead to a decrease in the quantity demanded of it. However, since the coefficient is less than one in absolute value, the demand for sachet water is income inelastic. An increase in income brings about less than propotionate decrease in the quantity demanded of sachet water. Specifically, 1 percent increase in income brings about $0.0035 \%$ decrease in the qauntity of sachet water demanded. The t-value and the p-value of the coefficient of $\mathrm{Y}$ show that it is statistically significantly different from zero at $5 \%$ level of significance. 
From the above results, it is clear that demand for sachet water is both own price, cross price and income inelastic. This means that any tax imposed on the producers will be easily transferred to the the final consumers through the sellers without affecting the quantity demanded significantly.

Figure 5 in appendix $\mathrm{A}$ is a summary of the proposal for sustainable sachet waste management in Nigeria. From the point of sachet production, the flow of the sachet is represented by the black arrow, and the flow of cash is represented by the red arrow. The producers move the sachet water to the sellers (whole sale and retailers) and in turn, collect payment that is equal to the sum of the economic and social cost of the product. The sellers in turn supply the sachet water to the end users at a cost that is equal to the sum of economics and social cost. The sachet water users have two options left for them; use the water and take the sachet to the collection point in return for payment of the social cost equivalent or use the water, drop it any how and lose an amount equal to the social cost. If the users resort to the later alternative, the trash pickers will pick these sachet bags and take them to the collection point where they will be paid an amount equal to the social cost of the pollution. The collection body will take these sachets to the appropriate agents for proper handling.

\subsection{Conclusion and recommendations}

Solid waste and plastic waste in particular possess a lot of danger to the environment and health of the people in the developing countries of the world. Larger proportion of this plastic wastes come from the production and consumption of sachet water. In Nigeria as is the case in most of the developing countries, there is no effective and consistence way of managing these wastes. This study therefore concentrated on finding the effective way of managing the plastic waste, using sachet water bags as a case study.

The survey was conducted in three states namely, Anambra, Enugu and Lagos with a total random sample of 1500. The analysis was done using both descriptive statistics and regression analysis. The finding of the research is that the programme of Plastic polluter Pay (PPP) can be effective and consistence in tackling this problem. In principle, the PPP levy system spreads the responsibility of management of plastic waste among three key stakeholders: the producers of the plastics, the consumers of the plastics and the appropriate authorities responsible for plastic waste management. The concept is to be able to create direct value in plastic wastes such that people will be willing to collect them from the ground. Since most waste scavengers in Nigeria would quickly pick up metallic waste because locally now it has ready market. It is, therefore, envisaged that if market value could be created in plastic waste, scavengers would start picking them as well.

The survey result show that more than half of the sample is of the opinion that $100 \%$ PPP levy will be sufficient to induce consumers to retain and return their used sachets water bags to the collection point to reclaim their money or cause trash collector to collect them and be paid the amount. The regression result show that sachet water demand is both own and cross price inelastic and therefore, support the idea of PPP levy as any levy on the producers can be easily transferred to the consumers without a significant change in the demand for the product.

The paper therefore recommend that the Nigerian government, specifically the ministry of environment through the Environmental Protection agency should try and adopt the PPP system in the sachet water industry and possibly extend it to the entire plastic production industries. This is believed will reduce to the minimum, the negative environmental impact of these products for the betterment of her citizens.

\section{References}

Adekunle L.V. et al (2005). "An Assessment of the Health and Social Economi Implications of sachet water in Ibadan Nigeria: A Public Health Challenge" Department of Epidemiology, Biostatistics \& Environmental Health, Faculty of Public Health, College of Medicine, University of Ibadan.

Adewumi I. Kenny (2006). "Solid Waste Management in Nigeria: Efforts towards a Paradigm Shift from Waste-to-Wealth Stratagems". The Fourth African Roundtable on Sustainable Consumption and Production (ARSCP-4)

Archer E., et al (1997). "Privatization of Refuse Management in Atonsu Kumasi, Ghana" Research Papers No. 7, University of Science and Technology, Kumasi and University of Amsterdam, Amsterdam.

Babatunde M. Adetunji and Biala M. Ilias (2010). "Externality Effects of Sachet Water Consumption and the Choice of Policy Instruments in Nigeria: Evidence from Kwara State" J Economics, 1 (2): 113-131 (2010)

Baumol, W. J. (1972), "On Taxation and the Control of Externalities", American Economic Review 62 (3): 307-322, JSTOR 1803378.

Coase, Ronald H. (1960). "The Problem of Social Cost". Journal of Law and Economics 3 (1): 1-44. 
Edoga M.O., Onyeji L.I., Oguntosin O.O., (2008). “Achieving Vision 20:2020 Through Waste Produce Candle”. Journal of Engineering and Applied Sciences, 3(8): 642-646.

Fobil1 J. and Hogarh J. (2003). "The Dilemmas of Plastic Wastes in a Developing Economy: Proposals for a Sustainable Management Approach for Nigeria"

Globe net market report, (2007). "Nigerian Waste Management"

Gujarati D. N, (2003), 'Basic Econometrics” $4^{\text {th }}$ Ed. Tata McGraw Publishing Company Limited, New Delhi

KMA, (1995). "Strategic Sanitation Plan for Kumasi 1996-2005”. Kumasi, Ghana.

Mojekeh, M.O. and Eze P.A.O., (2011), "The Environmental Impact of Production and Sales of Sachet Water in Nigeria", African Research Review > Vol 5, No 4 (2011)

Nkwoh N. Benedicta, (2006). “Overview of Waste Management in Nigeri”: Nigeria/ANESA.

Offion O. (2012). “The Daunting Challenges of Waste Management”, Nigerian Observer, Jan 2012

Okeniyi, J. Olusegun and Anwan, E. Udonwan, (2012). "Solid Wastes Generation in Covenant University, Ota, Nigeria: Characterization and Implication for Sustainable Waste Management", J. Mater. Environ. Sci. 3 (2) (2012) 419424

Pigou, A. C. (1920). The Economics of Welfare. London: Macmillan.

Schweizer F. and Annoh C. K. (1996). "Privatization of Solid Waste Management in Ghana”, Trialog 48: 50

Thompson, Earl A. and Batchelder, Ronald (1974). "On Taxation and the Control of Externalities: Comment," The American Economic Review, 64(3): 467-471.

Usman M. A. , Alaje T. O., Ekwueme V. I., Adekoya T. E. (2012), “Catalytic Degradation Of Water Sachet Waste (Lpde) Using Mesoporous Silica Kit-6 Modified With 12 Tungstophosphoric Acid" Petroleum \& Coal 54 (2) 85-90, Available online at www.vurup.sk/petroleum-coal

WHO/ UNICEF, (2012), "Millennium Development Goal drinking water target met, Sanitation target still lagging far behind”, Joint News release, EMBARGOED: TUESDAY, 6 MARCH 2012, 03:30 A.M. EST/ 09:30 A.M. CET

Appendix A

Figure 1:

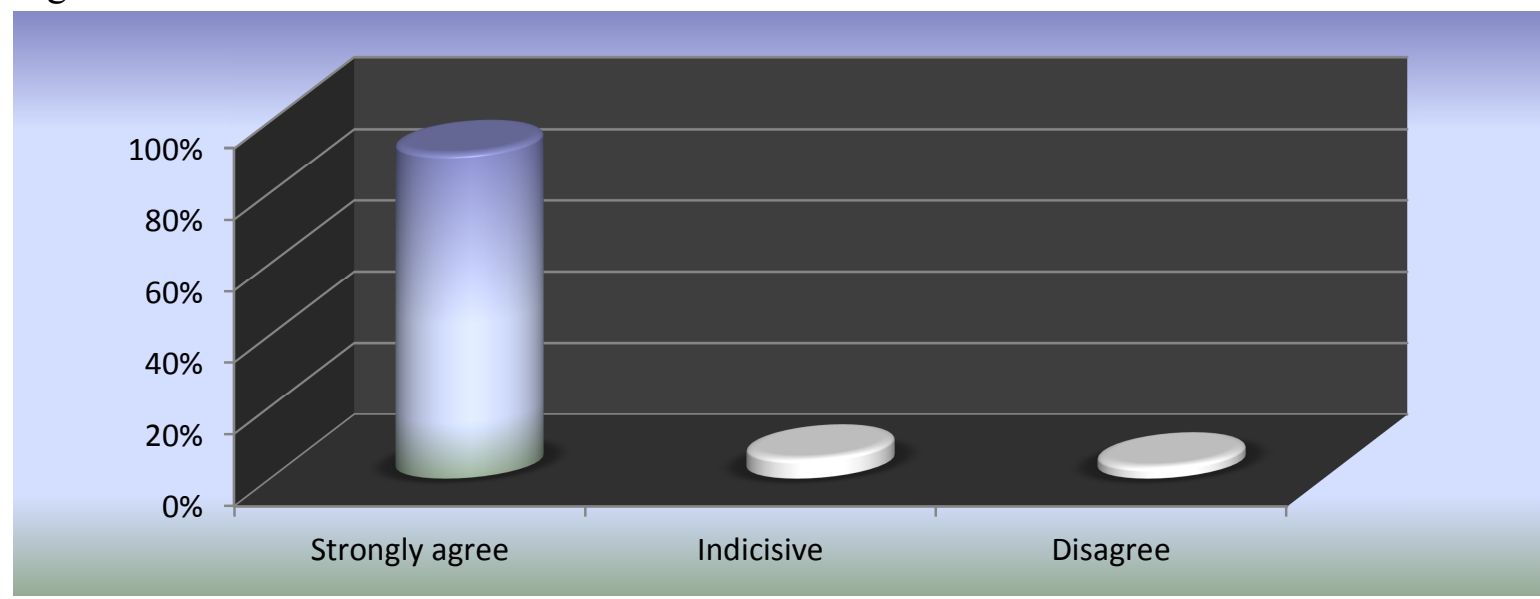

Sachet water production and consumption poses a lot of danger to our environment 


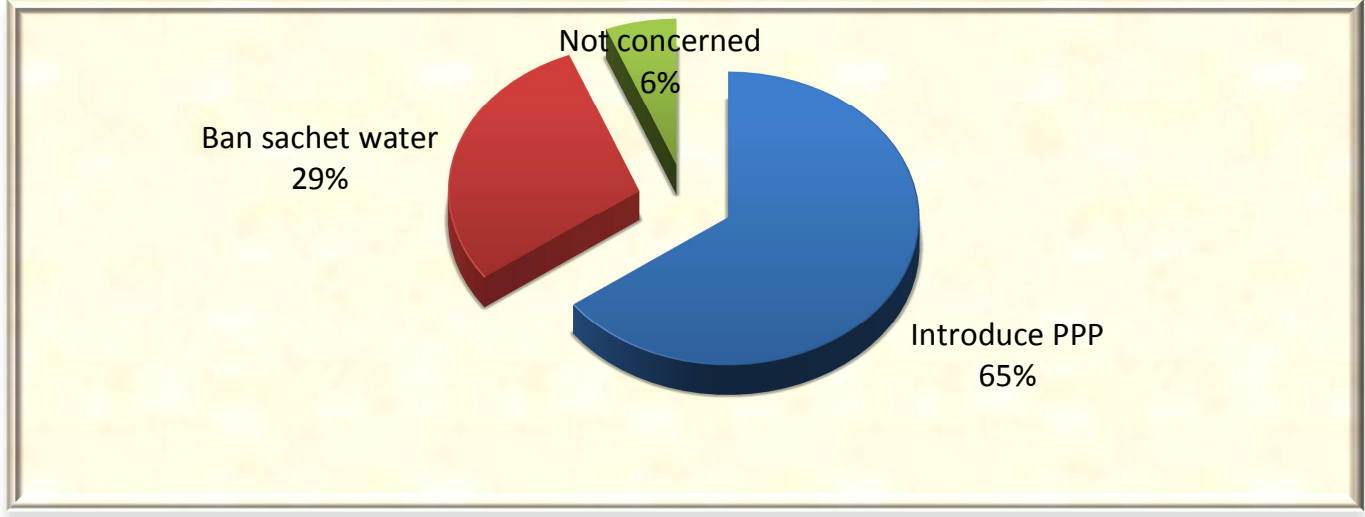

Figure 2:

People's opinion about sachet water

Figure 3

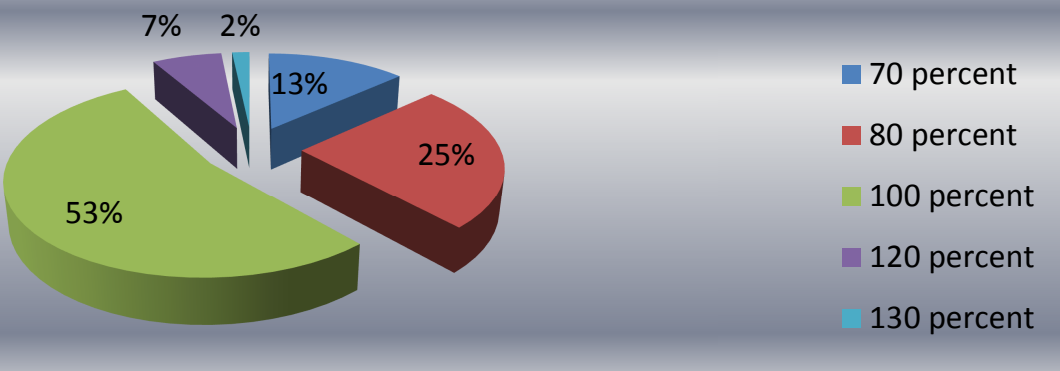

PPP levy as \% of sachet water price

Figure 4:

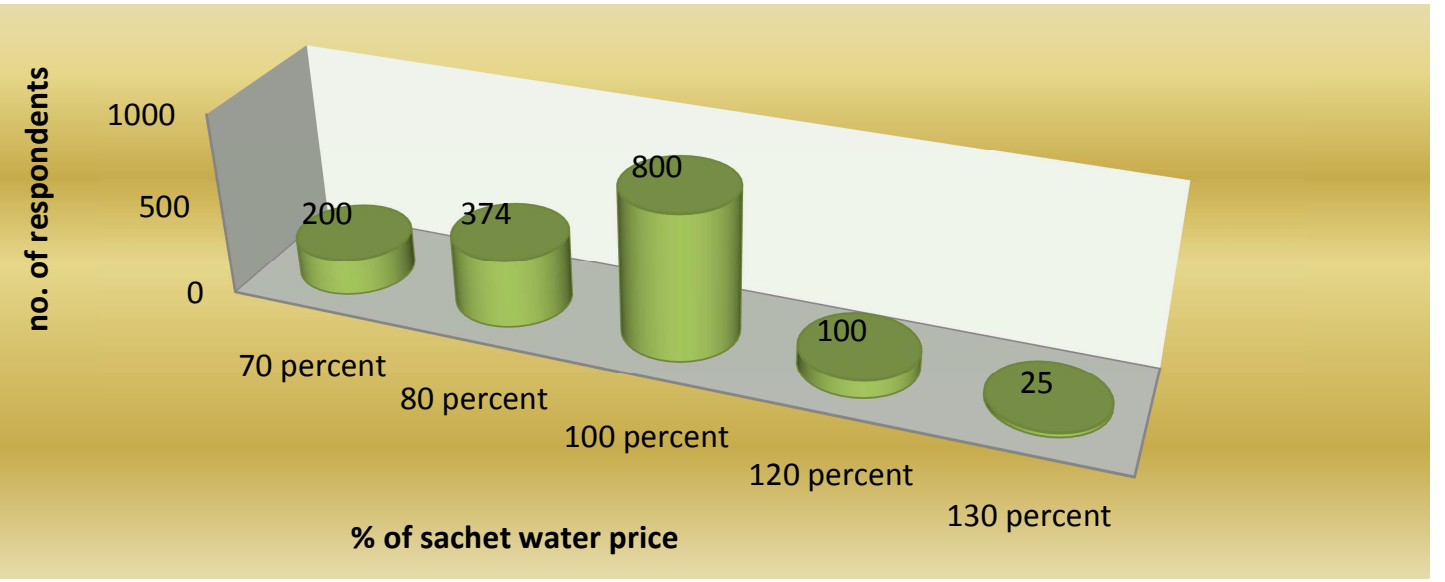

\section{PPP levy as \% of sachet water price}


Figure 5:

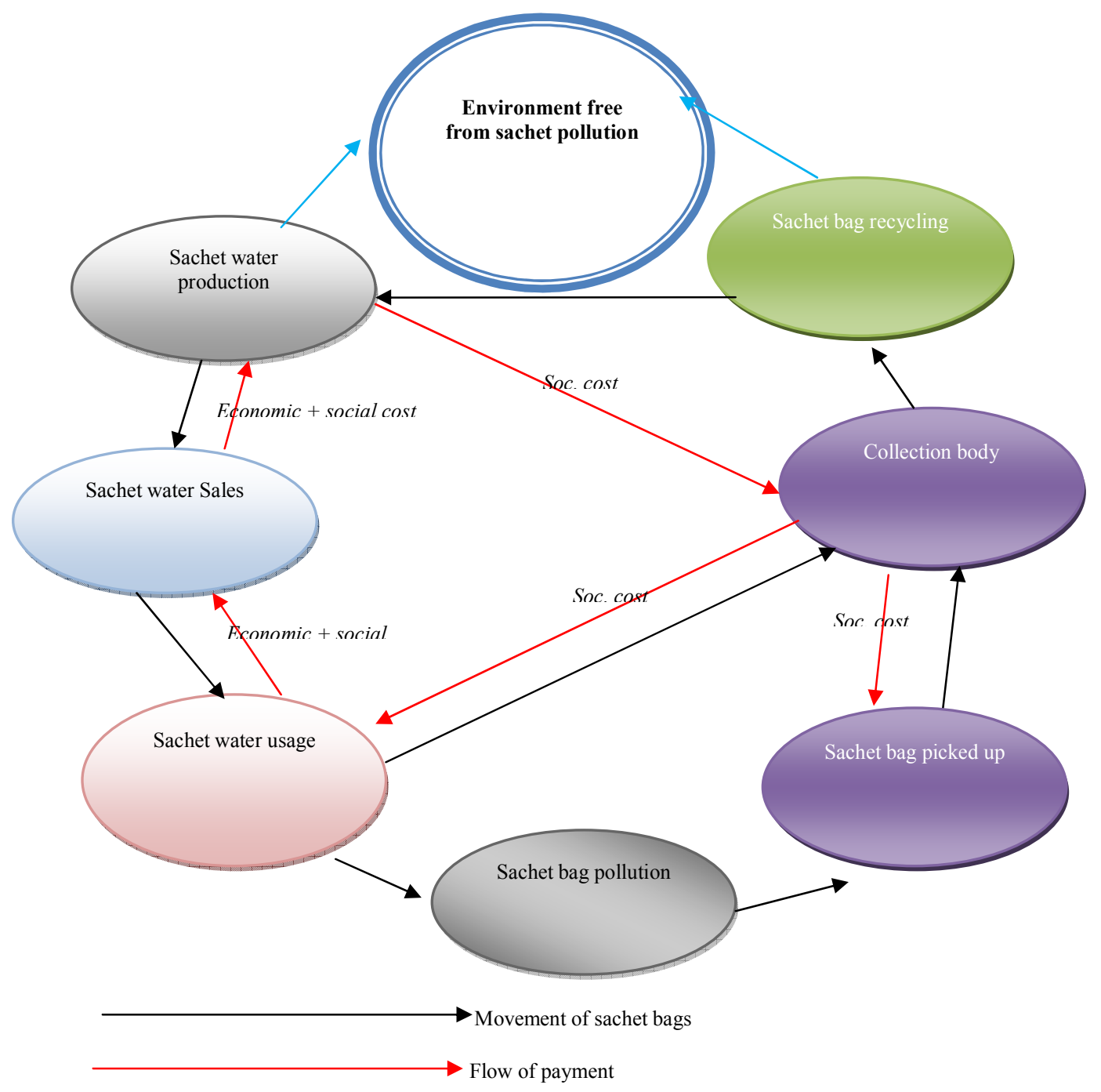

Summary of the proposal for sustainable sachet waste management in Nigeria

Table 1:

\begin{tabular}{llr|rl}
\hline variables & coefficients & Se & t-value & P value \\
\hline$\alpha_{0}$ & 1.0374 & 3.09118 & 0.3356 & 0.9332 \\
$P_{X}$ & -0.9321 & 0.266314 & -3.5 & 0.0003 \\
$P_{y}$ & 0.8743 & 0.174895 & 4.999 & 0.0000 \\
$P_{Z}$ & 0.2004 & 0.112043 & 1.7886 & 0.6543 \\
$Y$ & -0.0035 & 0.001746 & -2.005 & 0.0014 \\
\hline
\end{tabular}

Regression result 
This academic article was published by The International Institute for Science, Technology and Education (IISTE). The IISTE is a pioneer in the Open Access Publishing service based in the U.S. and Europe. The aim of the institute is Accelerating Global Knowledge Sharing.

More information about the publisher can be found in the IISTE's homepage: http://www.iiste.org

\section{CALL FOR PAPERS}

The IISTE is currently hosting more than 30 peer-reviewed academic journals and collaborating with academic institutions around the world. There's no deadline for submission. Prospective authors of IISTE journals can find the submission instruction on the following page: http://www.iiste.org/Journals/

The IISTE editorial team promises to the review and publish all the qualified submissions in a fast manner. All the journals articles are available online to the readers all over the world without financial, legal, or technical barriers other than those inseparable from gaining access to the internet itself. Printed version of the journals is also available upon request of readers and authors.

\section{IISTE Knowledge Sharing Partners}

EBSCO, Index Copernicus, Ulrich's Periodicals Directory, JournalTOCS, PKP Open Archives Harvester, Bielefeld Academic Search Engine, Elektronische Zeitschriftenbibliothek EZB, Open J-Gate, OCLC WorldCat, Universe Digtial Library, NewJour, Google Scholar

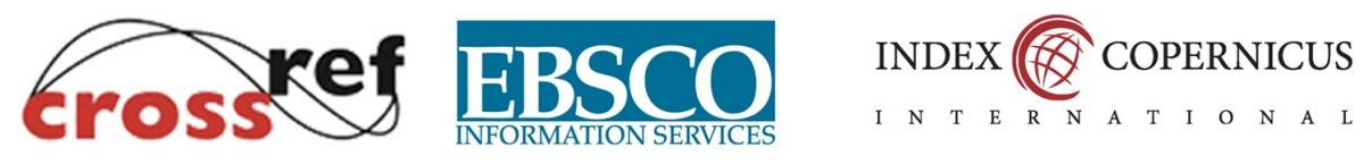

(O) ULRICHSWEB"

JournalTOCs

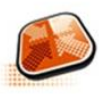

PKP | PUBLIC KNOWLEDGE PROJECT
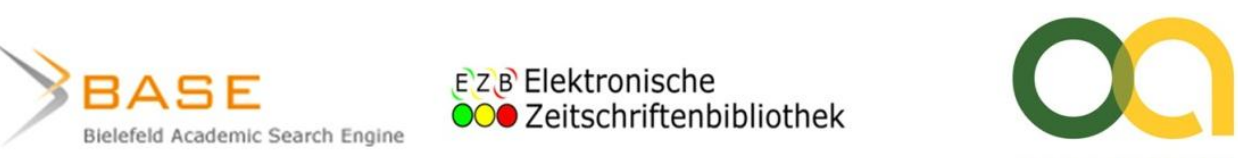

open access
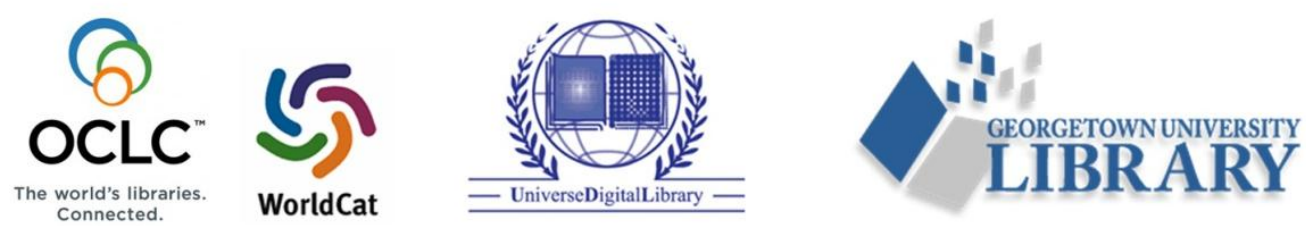